\title{
UTILIZAÇÃO DO GRÃO DE CEVADA EM SUBSTITUIÇÃO AO MILHO EM DIETAS PARA VACAS EM LACTAÇÃ̃
}

\section{(Utilization of barley grain in substitution of corn in diets for lactation cows)}

\author{
CÓRDOVA, H.A. ${ }^{\text {; }}$ THALER NETO, A. ${ }^{2}$; GOMES, I.P.O. ${ }^{2}$; SANTOS, I.R. ${ }^{3}$

\begin{abstract}
'Médico Veterinário - Centro Estadual de Educação Profissional Lysímaco Ferreira da Costa - Secretaria
${ }^{2}$ Depto. de Zootecnia - Centro de Ciências Agroveterinárias - Universidade do Estado de Santa Catarina (CAV/UDESC) - CEP 88.520-00 - Lages-SC. E-mail: thaler@cav.udesc.br; a2ipog@cav.udesc.br;
\end{abstract} \\ de Estado da Educação - Caixa Postal 27, CEP 83.880-000 - Rio Negro-PR. E-mail: a8hac@ibest.com.br; \\ ${ }^{3}$ Técnico em Agropecuária - Fundação ABC - Castro-PR.
}

\begin{abstract}
RESUMO - O objetivo deste trabalho foi avaliar os efeitos da substituição total e parcial de grãos de milho moídos por grãos de cevada laminados sobre a produção e a composição do leite. Foram utilizadas 28 vacas holandesas, com média de 125 dias de lactação, em um delineamento em quadrado latino $4 \times 4$. A dieta foi fornecida na forma de dieta totalmente misturada, 1 vez ao dia. Foram testados 4 níveis de substituição de milho por cevada (T1 - 0\% cevada; T2 - 33 \% cevada; T3 - 66\% cevada; e T4 - 100\% cevada). O experimento teve uma duração total de 105 dias. As vacas foram ordenhadas 2 vezes ao dia e as coletas para determinação da percentagem de gordura, proteína e extrato seco total (EST) e da contagem de células somáticas (CCS) realizadas 2 vezes em cada período experimental e para determinação do nitrogênio uréico no leite (NUL) ao final de cada período. A ingestão de matéria seca decresceu linearmente quando a cevada substituiu o milho. Aingestão de proteína bruta, fibra em detergente ácido e fibra em detergente neutro não foi afetada pela substituição do milho pela cevada. Foi observada redução linear na produção de leite, produção de leite corrigido para 4\% de gordura (LCG), produção e percentagem de gordura do leite, enquanto que a percentagem de proteína aumentou linearmente. A eficiência alimentar (EA) foi em média de $1,31 \mathrm{~kg}$ de $\mathrm{LCG} / \mathrm{kg}$ de matéria seca ingerida, não sendo afetada pelas dietas. Também não houve efeito do nível de substituição sobre a produção de proteína, EST, CCS e NUL.
\end{abstract}

Palavras-chave: cevada laminada, composição do leite, níveis, produção de leite.

ABSTRACT - In the present research work the effects of partial and total substitution of ground corn grain by dry rolled barley on the milk production and composition were evaluated. Twenty-eight Holstein cows with an average of 125 days in milk were used in a $4 \times 4$ latin square design. Once a day, the diet was supplied in a totally mixed ration. Four levels of corn substitution by barley were tested ( $\mathrm{T} 1-0 \%$ barley; $\mathrm{T} 2-33 \%$ barley;
T3 $-67 \%$ barley; and T4 - 100\% barley. The experiment was carried out during 105 days. Cows were milked twice a day and contents of fat, protein, milk total solids, and somatic cell count (SCC) were established twice in each treatment period and the milk urea nitrogen (MUN) at the end of each period. The dry matter intake decreased in a linear fashion when barley replaced corn in the diet. However, the ingestion of crude protein, neutral fiber detergent and acid fiber detergent were not affected when substituting corn by barley. Linear reduction was observed in milk yield, fat corrected milk production and fat and protein contents of the milk, while the protein percentages increased in a linear way. No effect was registered concerning the levels of substitution on the protein production, total solids of the milk, SCC, MUN and on the conversion efficiency.

Key-words: dry rolled barley, levels, milk yield, milk composition.

\section{Introdução}

No Brasil, especialmente na região sul, existem perspectivas favoráveis à produção de grãos que podem ser utilizados como alimentos alternativos na alimentação animal, principalmente grãos produzidos no inverno, como o triticale, o trigo, a aveia e a cevada.

Segundo IMAIZUMI (2002) a substituição de ingredientes tradicionais, como o milho, por outros de menor custo deve ser considerada, caso haja benefícios em termos econômicos e/ou nutricionais. O grão de cevada (Hordeum vulgare) é um dos subprodutos indicados para substituir o milho, inclusive com redução de custo em épocas em que o preço do milho está muito alto ou quando os estoques ao nível de propriedade ou região estão baixos (HUTJENS, 1996). O grão de cevada que apresenta mais de $12 \%$ de proteína bruta (PB) não é aceito pela indústria cervejeira, podendo ser usado para alimentação animal.

Em alguns trabalhos realizados em países de pecuária leiteira desenvolvida, comparando a cevada laminada com o milho, não foi encontrado efeito sobre

Autor para correspondência: André Thaler Neto - thaler@cav.udesc.br. 
a produção de leite. Em dez estudos incluindo somente a cevada ou milho nos tratamentos, a produção de leite foi similar em oito deles (KENNELLY et al., 1996). Por outro lado, KENNELLY et al. (2001) relataram que a substituição do milho pela cevada na dieta de vacas em lactação pode resultar na queda do pH ruminal, redução da digestão da fibra, da ingestão de matéria seca (IMS) e depressão da gordura do leite. Além disto, CASPER et al. (1999) relataram diminuição na produção de leite e IMS em relação ao peso vivo devido à substituição do milho pela cevada. Geralmente a adição de cevada à dieta reduz a digestibilidade total de todas as frações dos alimentos (OVERTON et al, 1995; OROZCO-HERNÁNDES et al., 1997).

BEAUCHEMIN et al. (1994) não encontraram efeito sobre o volume de leite corrigido para gordura (LCG) em dietas à base de cevada laminada com 32 a 40\% de fibra em detergente neutro (FDN), enquanto que o teor de gordura aumentou linearmente à medida em que a percentagem de FDN da dieta aumentou. A partir de diversos estudos BEAUCHEMIN e RODE (1998) propuseram $32 \%$ de FND na MS, enquanto o NRC (National Research Council, 2001) recomenda 34\% de FDN na MS em dietas baseadas em cevada.

Alguns estudos, em países de clima temperado, tem mostrando efeito da substituição do milho por cevada laminada sobre a composição do leite. CASPER et al. (1990) reportaram que a percentagem de gordura no leite foi menor para vacas alimentadas com cevada do que vacas alimentadas com milho. A percentagem de proteína no leite pode aumentar linearmente com o aumento da proporção de cevada na dieta (OVERTON et al., 1995). Entretanto, resultados de outras pesquisas (YANG et al. 1997; CASPER et al., 1999) divergem daqueles acima citados, ou seja, a inclusão de cevada na dieta de vacas leiteiras não afetou a composição do leite.

As pesquisas que utilizam subprodutos, principalmente cevada, nas dietas de vacas em produção têm mostrado resultados contraditórios e são poucos os trabalhos no Brasil, o que fez despertar o interesse por este estudo.

Este trabalho tem por objetivos avaliar os efeitos da substituição total e/ou parcial de grãos de milho moídos por grãos de cevada laminados na dieta sobre o consumo de matéria seca, produção, composição e qualidade do leite de vacas holandesas de alta produção, bem como, estimar os níveis de substituição mais adequados.

\section{Material e Métodos}

O trabalho foi conduzido na Granja Experimental Fazenda Capão Alto, situada em Castro, PR, de propriedade da Fundação $A B C$, no período de junho a setembro de 2004. As análises do leite foram realizadas na Associação Paranaense de Criadores de Bovinos da Raça Holandesa (APCBRH), situada em Curitiba, PR, e a determinação do nitrogênio uréico no leite (NUL) foi efetuada pela Clínica do Leite, pertencente à Escola Superior de Agricultura Luiz de Queiroz (ESALQ), em Piracicaba, SP. Os alimentos foram analisados no Laboratório de Bromatologia da Fundação ABC, Castro, PR.

Foram utilizadas 28 vacas holandesas, com média de 125 dias de lactação, produção média de leite de 26,60 $\mathrm{kg} /$ dia e peso vivo médio de $573 \mathrm{~kg}$, ao início do experimento. Os animais foram alojados em confinamento do tipo free stall em 4 lotes de 7 animais. Cada lote dispunha de comedouro e bebedouro coletivos.

Foram testados 4 níveis de substituição de milho por cevada, com base na matéria seca do concentrado (T1 - 0\% cevada; T2 - 33\% cevada; T3 - 66\% cevada e T4 $100 \%$ cevada). As dietas foram balanceadas no início do primeiro período experimental com base nas características de todos os lotes e mantidas para os demais períodos. As dietas eram compostas por concentrados (milho moído (784g/l) e/ou cevada laminada (42 kg/hectolitro) e farelo de soja), volumosos (silagem de milho e silagem pré-secada de azevém), núcleo mineral (macro, microminerais e vitaminas $A, D$, e E) e uma substância tamponante (bicarbonato de sódio). A relação volumoso:concentrado, baseada na ingestão diária de matéria seca (MS), foi ajustada para 57\%:43\%. A dieta totalmente misturada (DTM), fornecida 1 vez por dia, foi processada em carreta misturadora modelo vertical, sendo os concentrados e volumosos pesados individualmente, utilizando-se balança eletrônica para os minerais (núcleo, bicarbonato de sódio e cloreto de sódio). Dietas isoprotéicas foram formuladas prevendo $10 \%$ de sobra, encontrando-se a composição centesimal e química das mesmas na TABELA 1.

O experimento teve duração de 105 dias, constituído de um período de adaptação de 21 dias e 4 períodos de 21 dias. Os primeiros 5 dias de cada período serviram para adaptação gradativa à nova dieta $(50 \%$ de cevada e $50 \%$ de milho), os 9 dias seguintes para adaptação à dieta definitiva e para eliminar a influência de possíveis efeitos residuais e os 7 dias restantes para a coleta de amostras e dados. As produções individuais de leite (2 ordenhas diárias) foram registradas nos dias 18 e 21 de cada período, através de medidores eletrônicos, sendo coletadas amostras de leite para análises de gordura, proteína, extrato seco total (EST), contagem de células somáticas (CCS) e nitrogênio uréico no leite (NUL).

Todos os alimentos foram analisados no início do experimento e sempre que havia abertura de novo silo ou recepção de novo carregamento de concentrados. As sobras foram coletadas e pesadas todas as manhãs da semana de coleta de dados, sendo analisadas ao final de cada período experimental. Todos os alimentos, inclusive as sobras, foram analisados quanto à percentagem de MS, proteína bruta (PB), extrato etéreo $(E E)$, matéria mineral $(M M)$, fibra em detergente neutra (FDN) e fibra em detergente ácida (FDA). No milho e na cevada, além destes nutrientes, foi determinada a concentração de amido e a presença de micotoxinas (TABELA 2). 
Utilização do grão de cevada em substituição ao milho em dietas para vacas em lactação

TABELA 1 - INGREDIENTES E COMPOSIÇÃO QUÍMICA DAS DIETAS (\% NA MS; MÉDIA DOS QUATRO PERÍODOS EXPERIMENTAIS). (2004).

\begin{tabular}{|c|c|c|c|c|}
\hline \multirow[t]{2}{*}{ Item } & \multicolumn{4}{|c|}{ Níveis de substituição } \\
\hline & $0 \%$ & $33 \%$ & $67 \%$ & $100 \%$ \\
\hline \multicolumn{5}{|l|}{ Ingredientes } \\
\hline Silagem de milho & 30,15 & 30,93 & 31,19 & 32,16 \\
\hline Silagem pré-secada & & & & \\
\hline de azevém & 26,09 & 26,37 & 26,74 & 26,71 \\
\hline Cevada laminada & 00,0 & 9,04 & 18,11 & 27,28 \\
\hline Milho moído fino & 27,52 & 18,38 & 9,20 & 0,00 \\
\hline Farelo de soja & 13,84 & 12,87 & 12,34 & 11,42 \\
\hline Bicarbonato de sódio & 0,75 & 0,76 & 0,76 & 0,76 \\
\hline Cloreto de sódio & 0,24 & 0,24 & 0,24 & 0,24 \\
\hline Núcleo mineral $^{2}$ & 1,41 & 1,42 & 1,42 & 1,43 \\
\hline \multicolumn{5}{|l|}{ Composição química $^{3}$} \\
\hline MS & 49,85 & 49,13 & 48,83 & 48,85 \\
\hline PB & 13,52 & 13,19 & 13,94 & 13,26 \\
\hline FDA & 19,81 & 20,72 & 21,14 & 21,86 \\
\hline FDN & 35,71 & 37,46 & 38,82 & 40,57 \\
\hline $\mathrm{CNF}^{4}$ & 40,92 & 39,95 & 38,84 & 37,80 \\
\hline Amido & 29,26 & 27,16 & 26,68 & 25,07 \\
\hline $\mathrm{EL}, \mathrm{Mcal} / \mathrm{kg}^{5}$ & 1,64 & 1,63 & 1,62 & 1,60 \\
\hline
\end{tabular}

${ }^{1}$ Níveis de substituição de milho por cevada.

${ }^{2}$ Composição (por Kg): Vitamina A 200.00 Ul; vitamina D3 66.700 Ul; vitamina E 500 mg; cálcio 230 g; fósforo 80 g; magnésio $10 \mathrm{~g}$; enxofre $12 \mathrm{~g}$; sódio $68 \mathrm{~g}$; ferro $3.000 \mathrm{mg}$; cobre $680 \mathrm{mg}$; manganês 1.700 mg; zinco 3.000 mg; iodo 80 mg; selênio $22 \mathrm{mg}$; cobalto $15 \mathrm{mg}$; flúor $15 \mathrm{mg}$; antioxidante $100 \mathrm{mg}$.

${ }^{3}$ Estimada através do Spartan Ration Evaluator/Balancer for dairy cattle, versão 2.01 (Michigan University, 1992) com base nas análises bromatológicas dos ingredientes.

${ }^{4} \mathrm{CNF}$ - Carboidratos não fibrosos: $100-(\mathrm{PB}+\mathrm{FDN}+\mathrm{EE}+\mathrm{MM})$.

${ }^{5} \mathrm{EL}_{1}$ - Energia líquida para lactação dos concentrados foi obtida do NRC (1989); EL, dos volumosos foi estimada como segue: $\mathrm{Mcal} / \mathrm{kg}=2,863-0,0262 \%$ FDN (MERTENS, 1992).

TABELA 2 - COMPOSIÇÃO BROMATOLÓGICA MÉDIA DO MILHO TRITURADO E DA CEVADA LAMINADA (\% NA MATÉRIA SECA). (2004).

\begin{tabular}{|c|c|c|c|c|c|c|}
\hline & \multicolumn{3}{|c|}{ Milho triturado } & \multicolumn{3}{|c|}{ Cevada laminada } \\
\hline & Amostra 1 & Amostra 2 & Média & Amostra 1 & Amostra 2 & Média \\
\hline MS & 88,2 & 86,95 & 87,57 & 89,30 & 84,70 & 87,00 \\
\hline PB & 7,13 & 7,67 & 7,40 & 10,81 & 11,82 & 11,31 \\
\hline Extrato etéreo & 4,35 & 5,71 & 5,03 & 2,88 & 1,93 & 2,40 \\
\hline Cinzas & 1,08 & 1,16 & 1,12 & 2,03 & 2,25 & 2,14 \\
\hline FDA & 2,60 & 3,15 & 2,87 & 3,53 & 5,77 & 4,65 \\
\hline FDN & 9,51 & 9,97 & 9,74 & 19,90 & 19,32 & 19,61 \\
\hline Amido & 65,33 & 63,92 & 64,62 & 53,22 & 57,70 & 55,46 \\
\hline $\mathrm{CNF}^{1}$ & 78,10 & 75,50 & 76,80 & 63,60 & 64,70 & 64,15 \\
\hline Aflatoxina & $\mathrm{ND}^{2}$ & ND & & ND & ND & \\
\hline Zearalenona & ND & ND & & ND & ND & \\
\hline
\end{tabular}

${ }^{1} \mathrm{CNF}$ (Carboidratos não fibrosos): 100- (PB+FDN+EE+MM).

${ }^{2} \mathrm{ND}$ - Não detectado.

O experimento foi realizado em um delineamento em quadrado latino $4 \times 4$ balanceado, sendo cada quadrado repetido 7 vezes. As vacas foram agrupadas nos lotes de acordo com o número de lactações, estágio de lactação, peso vivo, produção de leite e sólidos, medidos durante o período pré-experimental. Foram formados 4 grupos com 7 vacas cada (4 vacas primíparas e 3 multíparas), sendo cada grupo submetido a um tratamento diferente em cada período experimental.

Para avaliação de ingestão de matéria seca (IMS),
PB, FDA, FDN cada grupo de 7 vacas submetido a um tratamento em um período foi considerado uma unidade experimental, sendo a análise conduzida em um único quadrado latino $4 \times 4$. Para produção e composição de leite a vaca foi considerada uma unidade experimental.

Foram analisadas as produções de leite, de leite corrigido para $4 \%$ de gordura (LCG), os percentuais e produção de proteína e gordura, extrato seco total (EST), escore de células somáticas (ECS), NUL, ingestão de matéria seca (IMS), PB, FDA, FDN e 
eficiência alimentar (EA). O ECS foi definido como logaritmo de base $2($ CCS $($ em milhares/100) +3$)$.

Os resultados foram submetidos à análise de variância utilizando-se a PROC GLM (General Linear Model) do pacote estatístico SAS (SAS INSTITUTE, 1991). Para cada variável foram analisados os efeitos da dieta, do período e do animal, sendo a influência dos níveis de substituição submetida à análise de regressão.

\section{Resultados e Discussão}

À medida que o nível de cevada na dieta aumentou, IMS decresceu linearmente $(P<0,05)$ (TABELA 3), na proporção de $0,01259 \mathrm{~kg}$ para cada $1 \%$ de substituição de milho por cevada (GRÁFICO 1). A menor IMS em dietas contendo níveis mais altos de cevada pode ser atribuída à maior concentração de FDN na MS. KENNELLY et al. (2001) atribuíram como causa da variação da IMS a diferença do $\mathrm{pH}$ ruminal e a maior concentração de ácido propiônico e ácido lático no rúmen em dietas contendo cevada. Autilização de dietas com alto nível de amido, no caso do presente experimento, 25 a $30 \%$ do total da MS (TABELA 1), incluindo fontes com diferentes degradabilidades deste carboidrato, também sugerem a possibilidade de diferenças na ingestão da MS.

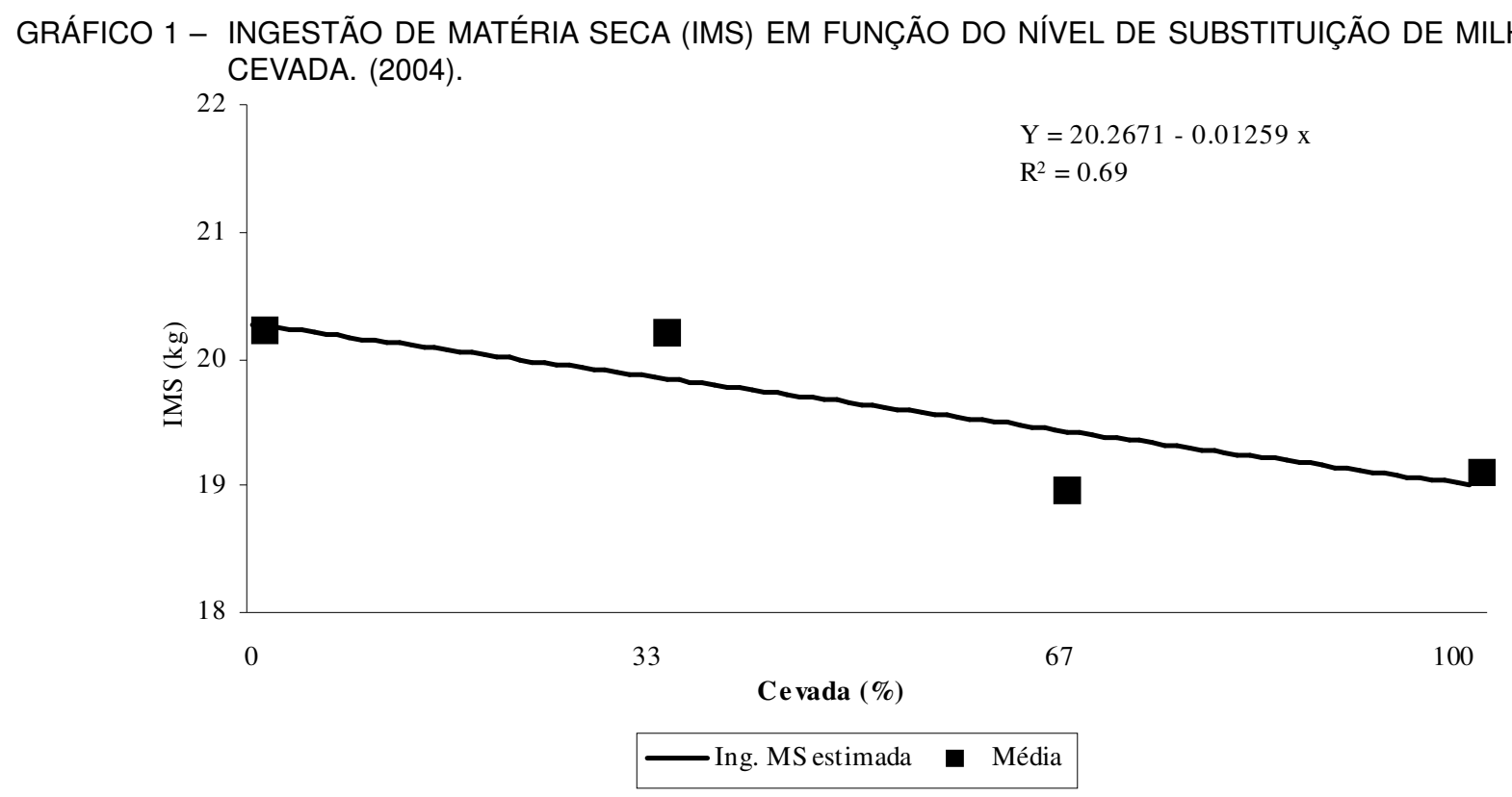

TABELA 3 - VALORES MÉDIOS, COEFICIENTE DE VARIAÇÃO (CV) E NÍVEIS DE SIGNIFICÂNCIA DA ANÁLISE DE REGRESSÃO PARA INGESTÃO DE MATÉRIA SECA (IMS), PROTEÍNA BRUTA (PB), FIBRA EM DETERGENTE ÁCIDO (FDA), FIBRA EM DETERGENTE NEUTRO (FDN) E EFICIÊNCIA ALIMENTAR (EA) DE ACORDO COM O NÍVEL DE SUBSTITUIÇÃO DE MILHO POR CEVADA. (2004).

\begin{tabular}{|c|c|c|c|c|c|c|c|}
\hline \multirow[b]{2}{*}{ Ítem } & \multicolumn{4}{|c|}{ Níveis de substituição ${ }^{1}$} & \multicolumn{3}{|c|}{ Regressão } \\
\hline & $0 \%$ & $33 \%$ & $67 \%$ & $100 \%$ & CV\% & Linear & Quadrática \\
\hline \multicolumn{8}{|l|}{ Ingestão } \\
\hline IMS, $\mathrm{kg} / \mathrm{d}$ & 20,22 & 20,20 & 18,97 & 19,10 & 3,71 & 0,0298 & $\mathrm{NS}^{2}$ \\
\hline $\mathrm{PB}, \mathrm{kg} / \mathrm{d}$ & 2,78 & 2,70 & 2,73 & 2,61 & 6,41 & NS & NS \\
\hline FDA, $\mathrm{kg} / \mathrm{d}$ & 3,82 & 3,98 & 3,78 & 4,08 & 5,41 & NS & NS \\
\hline $\mathrm{FDN}, \mathrm{kg} / \mathrm{d}$ & 6,91 & 7,16 & 7,07 & 7,28 & 5,29 & NS & NS \\
\hline Eficiência alimentar & & & & & & & \\
\hline EA, kg leite & 1,306 & 1,286 & 1,349 & 1,307 & 4,66 & NS & NS \\
\hline
\end{tabular}

${ }^{1}$ Níveis de substituição de milho por cevada.

${ }^{2} \mathrm{P}>0,05$.

$E A=$ Produção de leite corrigida para $4 \%$ de gordura/IMS. 
Não houve diferença significativa $(P>0,05)$ quanto à ingestão de PB, FDN e FDA (TABELA 3). Dados semelhantes foram obtidos por YANG et al. (1997). A produção de leite apresentou uma média geral de $26,95 \pm 0,12 \mathrm{~kg} / \mathrm{dia}$, decrescendo linearmente $(P<0,05)$ com o aumento do nível de cevada na dieta (TABELA 4). Observou-se um decréscimo de $0,008 \mathrm{~kg}$ de leite para cada $1 \%$ de acréscimo na substituição de milho por cevada (GRÁFICO 2). Considerando que a eficiência alimentar foi similar entre as dietas (TABELA 3), uma possível causa de redução na produção de leite em dietas à base de cevada (DBC) poderia ser a menor ingestão de matéria seca, em especial de amido, e conseqüentemente de EL, CASPER et al. (1999) especularam que o maior conteúdo de amido do milho em relação à cevada pode contribuir para uma produção maior de leite em dietas à base de milho (DBM).

\section{GRÁFICO 2 - PRODUÇÃO DE LEITE E DE LEITE CORRIGIDO PARA 4,0\% DE GORDURA (LCG4\%) EM FUNÇÃO DO NÍVEL DE SUBSTITUIÇÃO DE MILHO POR CEVADA. (2004).}

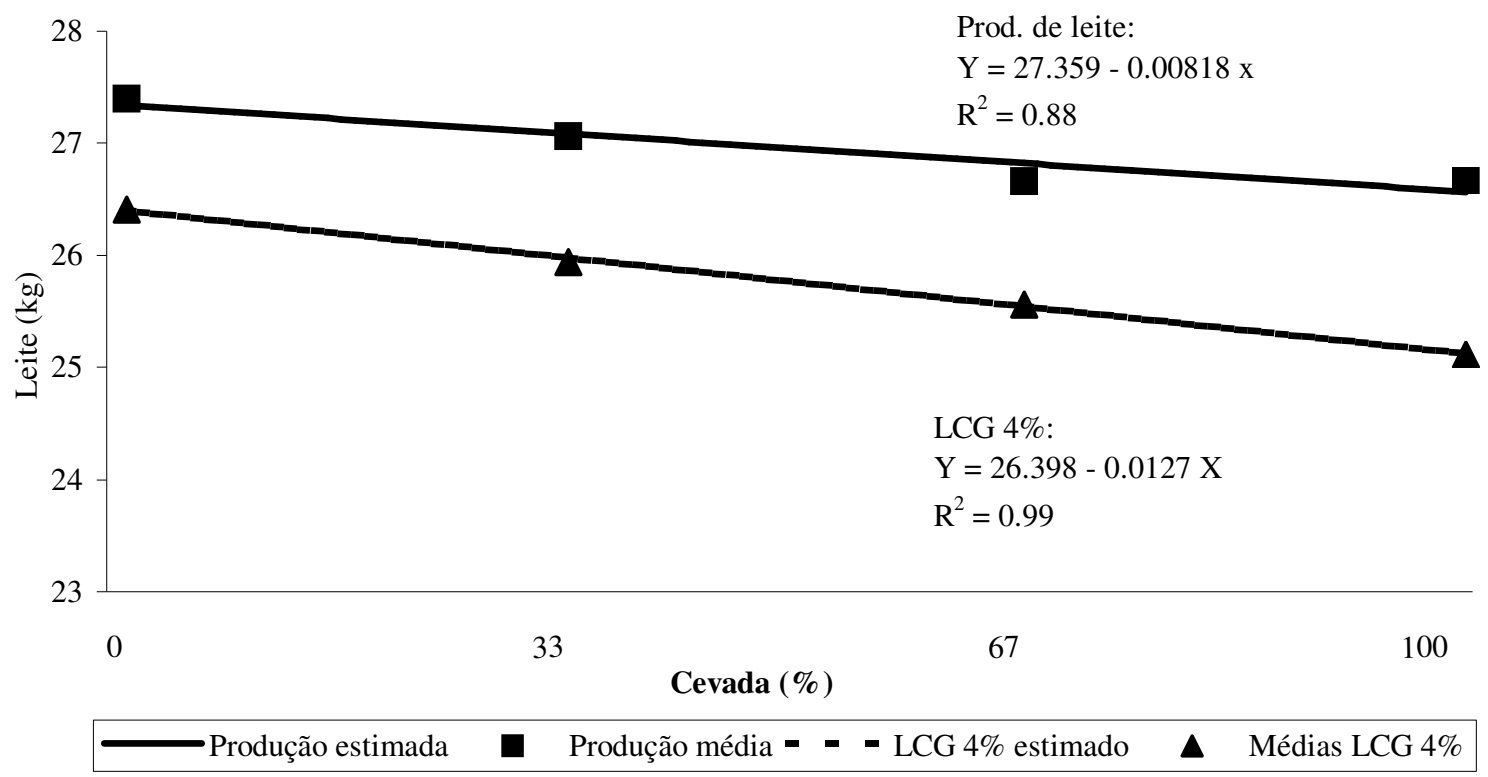

A produção de leite corrigido para $4 \%$ de gordura (LCG), também decresceu linearmente $(P<0,01)$, na ordem de $0,012 \mathrm{~kg}$ de leite para cada $1 \%$ de acréscimo na substituição de milho triturado por cevada laminada (TABELA 4 e GRÁFICO 2). Observou-se que a diminuição na produção de LCG foi mais acentuada do que a produção de leite, devido ao decréscimo no teor de gordura. A maior concentração de FDN, na dieta (TABELA 1) não foi suficiente para evitar a redução da produção de LCG. Resultados semelhantes foram observados por vários autores nos Estados Unidos (CASPER et al., 1990; OVERTON et al., 1995), os quais descreveram um decréscimo linear na IMS, produção de leite e LCG quando a cevada substituiu o milho. Porém, outros autores (BEAUCHEMIN e RODE, 1997; YANG et al., 1997) reportaram que em vacas alimentadas com milho e/ou cevada não houve diferença significativa na produção de LCG, na produção e composição do leite e na IMS.

A produção (kg/dia) (TABELA 4) e a percentagem de gordura do leite (TABELA 5 e GRÁFICO 3) decresceram linearmente $(P<0,01)$ quando a inclusão da cevada na dieta aumentou. Devido à rápida digestão ruminal do amido da cevada, a substituição do milho por cevada na dieta de vacas leiteiras pode resultar em queda do $\mathrm{pH}$ do rúmen, redução da digestão da fibra, da IMS e da percentagem de gordura do leite (KENNELLY et al., 2001).

A percentagem de proteína no leite aumentou de forma linear $(P<0,01)$ com a maior concentração de cevada na dieta (GRÁFICO 3 e TABELA 5), sem afetar a produção de proteína (kg/dia) (TABELA4). Resultados semelhantes foram obtidos por BEAUCHEMIN et al. (1997). Provavelmente isto deve-se ao fato de que dietas à base de cevada caracterizam-se por uma fermentação mais rápida e completa no rúmen em relação à dietas à base de milho. Como conseqüência proporciona mais energia disponível para os microorganismos do rúmen, aumentando a síntese de proteína microbiana e com isso proporcionando um maior fluxo de aminoácidos disponíveis para a síntese de proteína no leite (OVERTON et al., 1995; YANG et al., 1997).

Não houve diferença significativa $(P>0,05)$ no $E S T$, nos níveis de NUL, na CCS (TABELA 5) e na EA, (média de 1,31 $\pm 0,02 \mathrm{~kg}$ de LCG $/ \mathrm{kg}$ de MS) (TABELA 3). Os valores da EA situam-se dentro dos limites preconizados por BRITT et al. (2003). 
GRÁFICO 3 - PERCENTAGEM DE GORDURA E DE PROTEÍNA DO LEITE EM FUNÇÃO DO NÍVEL DE SUBSTITUIÇÃO DE MILHO POR CEVADA, (2004).

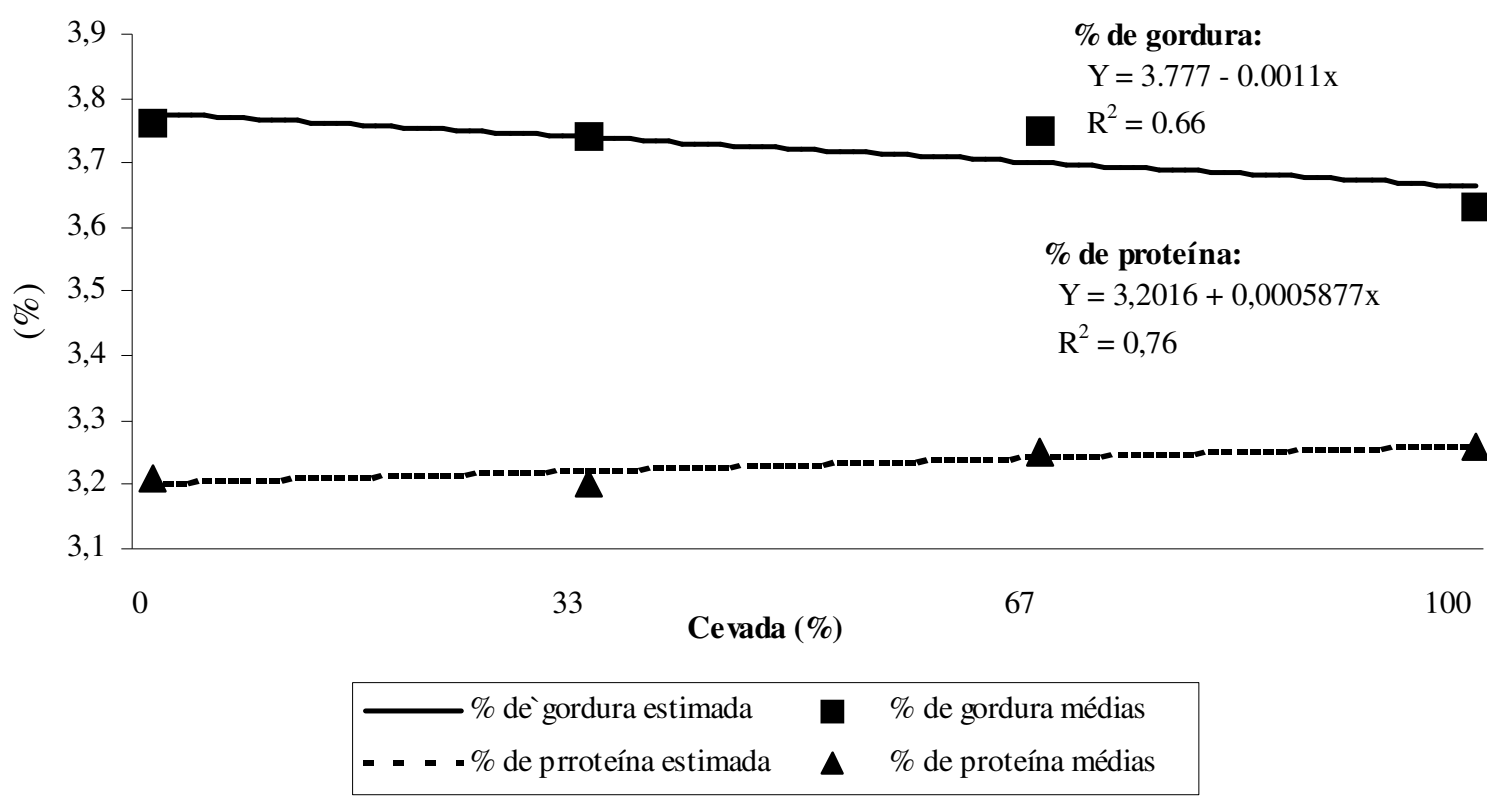

TABELA 4 - VALORES MÉDIOS, COEFICIENTE DE VARIAÇÃO (CV) E NÍVEIS DE SIGNIFICÂNCIA DA ANÁLISE DE REGRESSÃO PARA PRODUÇÃO DE LEITE, LEITE CORRIGIDO PARA 4\% (LCG4\%), GORDURA E PROTEÍNA DE ACORDO COM O NÍVEL DE SUBSTITUIÇÃO DE MILHO POR CEVADA. (2004).

\begin{tabular}{lccccccc}
\hline & \multicolumn{5}{c}{ Níveis de substituição $^{1}$} & \multicolumn{3}{c}{ Regressão } \\
\cline { 2 - 8 } \multicolumn{1}{c}{ Ítem } & $0 \%$ & $33 \%$ & $67 \%$ & $100 \%$ & CV\% & Linear & Quadrática \\
\hline Produção leite & & & & & & & \\
Leite, $\mathrm{kg} / \mathrm{d}$ & 27,43 & 27,07 & 26,64 & 26,66 & 4,60 & 0,0125 & $\mathrm{NS}^{2}$ \\
LCG 4\%, kg/d & 26,41 & 25,94 & 25,56 & 25,11 & 5,20 & 0,0004 & $\mathrm{NS}$ \\
Gordura, kg/d & 1,029 & 1,007 & 0,993 & 0,963 & 6,23 & 0,0002 & NS \\
Proteína, kg/d & 0,878 & 0,863 & 0,863 & 0,865 & 5,24 & NS & NS \\
\hline
\end{tabular}

${ }^{1}$ Níveis de substituição de milho por cevada.

${ }^{2} \mathrm{P}>0,05$.

TABELA 5 - VALORES MÉDIOS, COEFICIENTE DE VARIAÇÃO (CV) E NÍVEIS DE SIGNIFICÂNCIA DA ANÁLISE DE REGRESSÃO PARA PERCENTAGEM DE GORDURA E DE PROTEÍNA, EXTRATO SECO TOTAL, ESCORE DE CÉLULAS SOMÁTICAS (ESC) E NITROGÊNIO URÉICO NO LEITE (NUL) DE ACORDO COM O NÍVEL DE SUBSTITUIÇÃO DE MILHO POR CEVADA. (2004).

\begin{tabular}{lccccccc}
\hline & \multicolumn{4}{c}{ Níveis de substituição } & \multicolumn{3}{c}{ Regressão } \\
\cline { 2 - 9 } & $0 \%$ & $33 \%$ & $67 \%$ & $100 \%$ & CV\% & Linear & Quadrática \\
\hline Ítem & & & & & & & \\
$\quad$ Gordura, \% & 3,76 & 3,73 & 3,75 & 3,63 & 4,21 & 0,0061 & $\mathrm{NS}^{2}$ \\
$\quad$ Proteína, \% & 3,21 & 3,20 & 3,25 & 3,26 & 1,72 & 0,0001 & $\mathrm{NS}$ \\
$\quad$ Extrato seco total,\% & 12,68 & 12,61 & 12,67 & 12,58 & 1,63 & $\mathrm{NS}$ & $\mathrm{NS}$ \\
Qualidade do leite & & & & & & & $\mathrm{NS}$ \\
$\quad$ ECS & 2,90 & 3,12 & 3,40 & 2,90 & 23,65 & $\mathrm{NS}$ & $\mathrm{NS}$ \\
NUL, mg/dl & 11,40 & 10,98 & 10,88 & 11,09 & 12,77 & $\mathrm{NS}$ & \\
\hline
\end{tabular}

${ }^{1}$ Níveis de substituição de milho por cevada.

${ }^{2} \mathrm{P}>0,05$. 
Utilização do grão de cevada em substituição ao milho em dietas para vacas em lactação

Na TABELA 6 é apresentada uma avaliação econômica da substituição do milho por cevada, em função dos resultados do presente experimento. Foram considerados para fins de cálculo a produção de leite e os teores de gordura e proteína estimados a partir de equações de regressão da produção e composição do leite em função do nível de substituição de milho por cevada (TABELA 4 e 5). Para a formação dos preços do leite considerou-se um rebanho com produção diária de 750 litro/dia e teores de gordura e proteína apresentados na TABELA 6 (preços pagos pelo Pool ABC de comercialização de leite - Castro/PR em dezembro/ 2004).

TABELA 6 - AVALIAÇÃO ECONÔMICA DA SUBSTITUIÇÃO DO MILHO POR CEVADA. (2004).

\begin{tabular}{|c|c|c|c|c|}
\hline \multirow[t]{2}{*}{ İtem } & \multicolumn{4}{|c|}{ Níveis de substituição ${ }^{1}$} \\
\hline & $0 \%$ & $33 \%$ & $67 \%$ & $100 \%$ \\
\hline Preço/litro leite ${ }^{2}, \mathrm{R} \$$ & 0,5674 & 0,5668 & 0,5663 & 0,5657 \\
\hline Produção diária/vaca ${ }^{3}$, litro & 27,36 & 27,09 & 26,81 & 26,54 \\
\hline Gordura ${ }^{4}, \%$ & 3,78 & 3,74 & 3,70 & 3,66 \\
\hline $\begin{array}{l}\text { Proteína }{ }^{5}, \% \\
\text { Receita bruta diária/vaca, } \mathrm{R} \$ \\
\text { Custo alimentação/vaca/dia }{ }^{6}, \mathrm{R} \$ \\
\text { Retorno sobre custo de alimentação/vaca/dia }{ }^{7}, \mathrm{R} \$\end{array}$ & $\begin{array}{l}3,26 \\
15,52 \\
7,06 \\
8,46\end{array}$ & $\begin{array}{l}3,28 \\
15,35 \\
6,72 \\
8,63\end{array}$ & $\begin{array}{l}3,30 \\
15,18 \\
6,48 \\
8,70\end{array}$ & $\begin{array}{c}3,32 \\
15,01 \\
6,18 \\
8,83\end{array}$ \\
\hline Custo de alimentação/litro de leite, $\mathrm{R} \$$ & 0,258 & 0,248 & 0,242 & 0,233 \\
\hline
\end{tabular}

${ }^{1}$ Níveis de substituição de milho por cevada.

${ }^{2}$ Preço ao produtor (Pool ABC - Castro/PR) - dezembro/2004.

${ }^{3}$ Estimada a partir da equação $Y=27,359-0,00818 x$ (Tabela 3).

${ }^{4}$ Estimada a partir da equação $Y=3,777-0,00114 x$ (Tabela 4).

${ }^{5}$ Estimada a partir da equação $Y=3,260+0,0005877 x$ (Tabela 4).

${ }^{6}$ Estimado a partir do custo dos alimentos - dez/2004, sendo silagem de milho $R \$ 0,12 / \mathrm{kg} M S$; silagem pré-secada de azevém $R \$ 0,25 / \mathrm{kg}$ MS; farelo de soja $R \$ 560,00 / T$; milho triturado $R \$ 350,00 / T$; cevada laminada $R \$ 262,50 / T$; bicarbonato de sódio $R \$ 1,35 / \mathrm{kg}$; núcleo mineral $R \$ 1,48 / \mathrm{kg}$; cloreto de sódio $R \$ 0,26 / \mathrm{kg}$.

${ }^{7}$ Receita bruta menos o custo com alimentação.

O custo de alimentação ficou mais baixo nos níveis mais altos de inclusão da cevada na dieta. Esse custo menor pode ser atribuído em parte ao preço da cevada que não atinge padrão cervejeiro, a qual apresenta um preço de aproximadamente $75 \%$ do preço de mercado do milho (valores de dezembro de 2004) e pela menor participação do farelo de soja na dieta (TABELA 1). Apesar da diminuição da produção de leite observouse maior retorno sobre custo de alimentação/vaca e menor custo de alimentação por litro de leite com a substituição do milho por cevada, devido à redução no custo de alimentação. A substituição completa do milho pela cevada resultou em um aumento no retorno sobre o custo de alimentação de $R \$ 0,37 / \mathrm{vaca} /$ dia e uma redução no custo de alimentação de $R \$ 0,025 /$ de leite produzido (TABELA 6). Tendo em vista a crescente valorização da composição do leite o aumento na percentagem de proteína do leite observado nos animais alimentados com dietas à base de cevada poderá compensar, ainda que parcialmente, o menor teor de gordura obtido com estas dietas.

\section{Conclusões}

De forma geral, neste estudo foi observada menor IMS, produção de leite, LCG4\%, produção e percentagem de gordura e maior percentagem de proteína do leite. A substituição de milho pela cevada não afetou a ingestão de PB, de FDA, de FDN, a produção de proteína do leite, o EST, a CCS, o NUL e a EA.

As alterações nos custos dos ingredientes das dietas, principalmente, da cevada, do milho e do farelo de soja, podem determinar maior ou menor vantagem na utilização da cevada na alimentação de vacas em produção, bem como o nível mais adequado de substituição.

\section{Referências}

BEAUCHEMIN, K. A.; RODE, L. M.; SCHAALJE, G. B. Optimal neutral detergent fiber concentracion of barleybased diets for lactating dairy cows. Journal of Dairy Dairy Science, Champaign, v. 77, n. 4, p. 1013-1029, 1994.

BEAUCHEMIN, K. A.; RODE, L. M. Minimum versus optimun concentrations of fiber in dairy cow based on barley silage and concentrates of barley or corn. Journal of Dairy Science, Champaign, v. 80, n. 8, p. 1629-1639, 1997.

BEAUCHEMIN, K. A.; RODE, L. Effective fiber in barleybased diets. Alberta, 1998. Disponível em: < http:// www.wcds.afns.ualberta.ca/Proceedings/1998/ ch14.htm>. Acesso em: 20 maio 2004. 
BEAUCHEMIN, K. A.; YANG, W. Z.; RODE, L. M. Effects of nonstructural carbohydrates and source of cereal grain in high concentrate diets of dairy cows. Journal of Dairy Science, Champaign, v. 80, n. 8, p. 1640-1950, 1997.

BRITT, J. S.; THOMAS, R.C.; SPEER, N. C.; HALL, M. B. Efficiency of converting nutrient dry matter to milk in Holstein herds. Journal of Animal Science, Champaign, v. 86, n. 11, p. 3796-3801, 2003.

CASPER, D. P.; SCHINGOETHE, D. J.; EISENBEISZ, W. A. Response of early lactation dairy cows fed diets varying in source of nonstructural carbohydrate and crude protein. Journal of Dairy Science, Champaign, v. 73, n. 4, p. 1039-1050, 1990.

CASPER, D. P.; MAIGA, H. A.; BROUK, M. J.; SCHINGOETHE, D. J. A. Synchronization of carbohydrate and protein sources on fermentation an passage rates in dairy cows. Journal of Dairy Science, Champaign, v. 82, n. 8, p. 1779-1790, 1999.

HUTJENS, M. Estratégias para los precios elevados que tiene atualmente el maíz. Hoard's Dairyman en español, Tlalnepantla, Mx, n. 7, p. 668, ago. 1996.

IMAIZUMI, H. Utilização do farelo de algodão como substituto do farelo de soja em dietas para vacas holandesas em lactação. In: REUNIÃO ANUAL DA SOCIEDADE BRASILEIRA DE ZOOTECNIA, XXXIX., 2002, Recife. Anais eletrônicos...Recife: UFRPE, 2002. CD-ROM 6.

KENNELLY, J.; OKINE, E.; KHORAZANI, R; CORBETT, R. Barley grain for dairy cattle. Alberta, 1996. Disponível em: <http://www.westerndairyscience.com $/ \mathrm{html}>$. Acesso em 09 maio 2003.
KENNELLY, J.; OKINE, E.; KHORAZANI, R; CORBETT, R. Barley grain for dairy cattle. Alberta, 2001. Disponível em: <http:// www.wcds.afns.ualberta.ca/Hosted/DRT/Articles/ Barley_Dairy.asp>. Acesso em 25 abr. 2004.

MERTENS, D.R. Análise da fibra e sua utilização na avaliação e formulação de rações. In: SIMPÓSITO INTERNACIONAL DE RUMINANTES, REUNIÃO ANUAL DA SOCIEDADE BRASILEIRA DE ZOOTECNIA, 29, Lavras, 1992. Anais... Lavras, SBZ, 1992. p. $188-219$.

OROZCO-HERNÁNDEZ, J. R.; BRISSON, G. J.; GIRARD, V. Timothy grass or alfafa silage for cows im midlalactation: effect of supplementary barley. . Journal of Dairy Science, Champaign, v.80, n. 11, p. 2876-2882, 1997.

OVERTON, T. R., CAMERON, M. R.; ELLIOTT, J. P.; CLARK, J. H.; NELSON, D. R. 1995. Ruminal fermentation and passage of nutrients to the duodenum of lactating cows fed mixtures of corn and barley. Journal of Dairy Science, Champaign, v. 78, n. 9, p. 1981-1998, 1995.

SAS INSTITUTE. Users guide: statistics: version 6.03. Cary, NC, 1991. v.2, 956 p.

YANG, W.Z.; BEAUCHEMIN, K.A.; KOENIG, K.M; RODE, L. M. Comparison of hull-less barley, barley, corn for lactating cows: effects on extent of digestion and milk production. Journal of Dairy Science, Champaign, v. 80, n. 10, p. 2475-2486, 1997.

Recebido para publicação:

$03 / 11 / 2005$

Aprovado: 